\title{
Parity improves anti-tumor immunity in breast cancer patients
}

\author{
Anna-Lena Krause ${ }^{1}$, Florian Schuetz ${ }^{2}$, Marc Boudewijns ${ }^{2}$, Maria Pritsch ${ }^{1}$, Markus \\ Wallwiener ${ }^{2}$, Michael Golatta ${ }^{2}$, Joachim Rom², Joerg Heil ${ }^{2}$, Christof Sohn ${ }^{2}$, Andreas \\ Schneeweiss ${ }^{2}$, Philipp Beckhove ${ }^{1,3, *}$ and Christoph Domschke ${ }^{2, *}$ \\ ${ }^{1}$ Translational Immunology Division, German Cancer Research Center (DKFZ), Heidelberg, Germany \\ ${ }^{2}$ Department of Gynecology and Obstetrics, Heidelberg University Hospital, National Center for Tumor Diseases (NCT), \\ Heidelberg, Germany \\ ${ }^{3}$ Regensburg Center for Interventional Immunology (RCI) and University Medical Center of Regensburg, Regensburg, Germany \\ Equal contributions \\ Correspondence to: Philipp Beckhove, email: beckhove@rcii.de \\ Christoph Domschke, email: christoph.domschke@med.uni-heidelberg.de \\ Keywords: pregnancy; breast cancer; anti-tumor $T$ cells; regulatory $T$ cells; tumor-associated antigens \\ Received: July 08, $2017 \quad$ Accepted: August 04, $2017 \quad$ Published: September 08, 2017 \\ Copyright: Krause et al. This is an open-access article distributed under the terms of the Creative Commons Attribution License \\ 3.0 (CC BY 3.0), which permits unrestricted use, distribution, and reproduction in any medium, provided the original author and \\ source are credited.
}

\section{ABSTRACT}

Compared to nulliparous women, parous women have an up to $\mathbf{5 0 \%}$ lower lifetime risk of developing breast cancer. An endogenous mechanism to prevent the development of cancer is the destruction of tumor cells by $T$ cells that recognize tumor-associated antigens (TAA). Since a number of TAA are also highly present in the breast and placenta of pregnant women, we investigated the induction and characteristics of spontaneous $T$ cell responses against TAA during pregnancy.

To this end, we collected peripheral blood from healthy nulliparous, primigravid and parous women, as well as from breast cancer patients. IFN-Y ELISpot assays were performed to measure the intensity and specificity of $T$ cell responses against 11 different TAA. The impact of TAA-specific Treg cells on anti-TAA responses was assessed by performing the assay before and after depletion of $C D 44^{+} \mathrm{CD} 25^{+} \mathrm{T}$ cells. The antigenic specificities of these Treg cells were analyzed by the Treg specificity assay. Furthermore, we conducted flow cytometric analyses to determine the memory phenotype and cytokine secretion profile of TAA-specific T cells.

Our results demonstrate that pregnancy induces functional and long-lived memory and effector $T$ cells that react against multiple TAA. These persist for many decades in parous females, but are not found in age-matched females without children. We also detected TAA-specific Treg cells, which suppressed strong effector $T$ cell responses after delivery. Nulliparous breast cancer patients displayed median TAA-specific effector $T$ cell responses to be decreased threefold compared to parous patients, which could be restored in vitro after depletion of Treg cells.

\section{INTRODUCTION}

Parity is associated with a $50 \%$ decreased lifetime risk of developing breast cancer [1]. However, the mechanisms behind the protective effect remain to be revealed. Since T cell immunity plays a major role in breast cancer prognosis, we here studied a potential influence of parity on breast tumor-specific $\mathrm{T}$ cell responses.

The hypothesis that lymphocytes can recognize and eliminate continuously-arising transformed cells was established during the late 1950s by Burnet and Thomas. To date, accumulating evidence supports this concept of "cancer immunosurveillance": Anti-cancer immune 
responses are initiated in many breast-, and other cancer patients upon recognition of tumor-associated antigens (TAA) by T lymphocytes [2, 3]. Both the presence of TAA-specific T lymphocytes in the blood $[4,5]$ and the accumulation of effector and memory $T$ cells [6] correlate with an improved survival of breast cancer patients. Thus, the strength of endogenous tumor-specific effector/ memory $\mathrm{T}$ cell responses determines the outcome of patients with breast cancer.

On the other hand, immune suppressive cells, such as $\mathrm{CD}^{+} \mathrm{CD}^{2} 5^{+}$regulatory $\mathrm{T}$ lymphocytes (Treg), can promote tumor growth. Treg cells play a major role in maintaining self-tolerance, but can also suppress the antitumor activity of TAA-specific effector T lymphocytes. Therefore, the intratumoral accumulation of Treg cells is associated with increased tumor grade, lymph node involvement, reduced overall survival and increased risk of relapse in breast cancer patients [7]. Accordingly, in vivo reduction of Treg cells with low-dose cyclophosphamide was shown to induce tumor-specific $\mathrm{T}$ cell responses in breast cancer patients, which correlated with improved survival [8].

Breast carcinomas overexpress a broad range of TAA which can be recognized by endogenous effector and regulatory T cells [9-11], including carcinoembryonic antigen (CEA), the melanoma-associated antigen (MAGE)-A3, mucin (MUC)-1, the human epidermal growth factor receptors EGFR and HER2, mammaglobin A and heparanase (HPA). Overexpression of TAA is already initiated in ductal carcinoma in situ, the most common preinvasive lesion of the breast [12]. Interestingly, many TAA are also associated with pregnancy. An increased expression of multiple TAAs was demonstrated, e.g., in the lactating breast, placenta and blood serum of pregnant women [13-15], and spontaneous effector T cell responses against one of these antigens, MUC-1, were observed in pregnant women [16]. Thus, it is conceivable that pregnancy might induce a population of endogenous breast tumor-specific memory $\mathrm{T}$ cells that could confer antitumor immunity to breast cancer patients. On the other hand, pregnancy is associated with an increased activity of immune tolerance mechanisms, including the induction of Treg cells, which prevent the mother's immune system to react against the embryo [17]. Therefore, the establishment of TAA-specific memory T cells in pregnant women might be inhibited or counterweighed by the induction of TAAreactive regulatory $\mathrm{T}$ cells during pregnancy or breast cancer development.

We here studied whether pregnancy results in the formation of long-lasting - protective, or inhibitory - $\mathrm{T}$ cell populations specific for breast cancer-associated antigens and whether such pregnancy-induced $\mathrm{T}$ cell responses do influence $\mathrm{T}$ cell immunity during breast cancer. We show that pregnancy induces long-lived memory and regulatory $\mathrm{T}$ cell responses against multiple breast cancer-associated antigens that persist for many decades, but are not found in age-matched females without children. Previous pregnancies thereby result in a median threefold increase of tumor antigen-specific effector T cells in parous compared to nulliparous breast cancer patients. In addition, tumor-specific T effector cell responses were strongly suppressed by TAA-reactive Treg in nulliparous women, while the presence of TAA-reactive Treg cells had only a moderate impact on TAA-reactive Teff cell responses in parous breast cancer patients. Taken together, our findings demonstrate that pregnancy results in a TAA-specific T cell memory, which lasts lifelong and which might improve anti-tumor immunity throughout breast cancer disease.

\section{RESULTS}

\section{Parous women harbor functionally active memory $T$ cells reactive against multiple breast tumor-associated antigens}

In a first set of experiments, we assessed the presence of TAA-specific $\mathrm{T}$ cells in parous compared to nulliparous healthy females. Therefore, we collected peripheral blood samples from 30 healthy volunteers (median age: 51.5 years, mean $45.8 \pm 11.7$ ) and performed interferon $\gamma\left(\right.$ IFN- $\gamma$ ) ELISpot assays with purified CD3 ${ }^{+}$ T cells and TAA-pulsed autologous dendritic cells (DCs) as antigen presenting cells. Donors aged 50 or older had participated in a mammography screening program and received an unsuspicious result. Primary IFN- $\gamma$ ELISpot data from two exemplary donors are presented in Figure 1A. Results were defined positive (red bars), when spot numbers of test wells containing TAAs were increased at least twofold over control wells containing a negative control antigen $(\mathrm{IgG})$ and the difference was statistically significant (asterisks).

We detected breast tumor-specific $\mathrm{T}$ cells in none of the nulliparous, but in $85 \%$ of parous women (Figure 1B). The T cell repertoire of parous women was highly polyvalent and directed against multiple different mammary epithelial-associated antigens (Figure 1C). A comparison of the total spot numbers between responding and non-responding donors verified that positive test results were not caused by low background spot numbers, but based on a significant increase in IFN- $\gamma$ secretion in response to single TAAs (Supplementary Figure 1). The intensity of spontaneous anti-tumor $\mathrm{T}$ cell responses was not depending on the age of the volunteers, the number of full-term pregnancies, age at first delivery or previous breastfeeding (Supplementary Figures 2A-2D). These findings suggest that a single full-term pregnancy per $s e$ triggers a robust and long-lasting TAA-specific T cell response in women. To substantiate this assumption we were lucky to obtain blood of monozygous female triplets with distinct reproductive history. Only in the triplet who had one full-term pregnancy TAA-reactive T cells were 
A

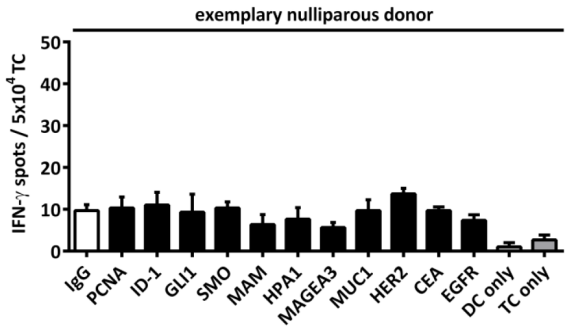

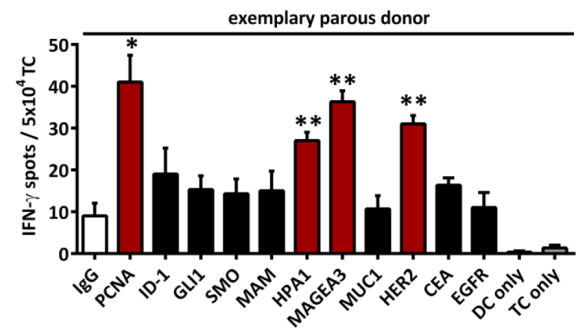

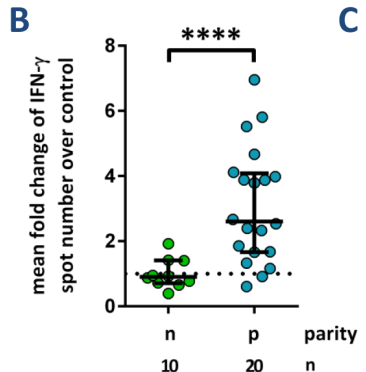

D

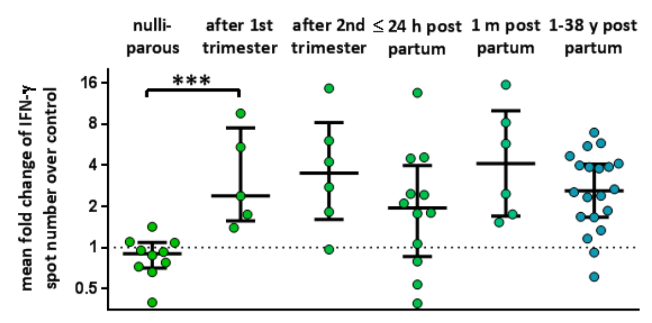

C
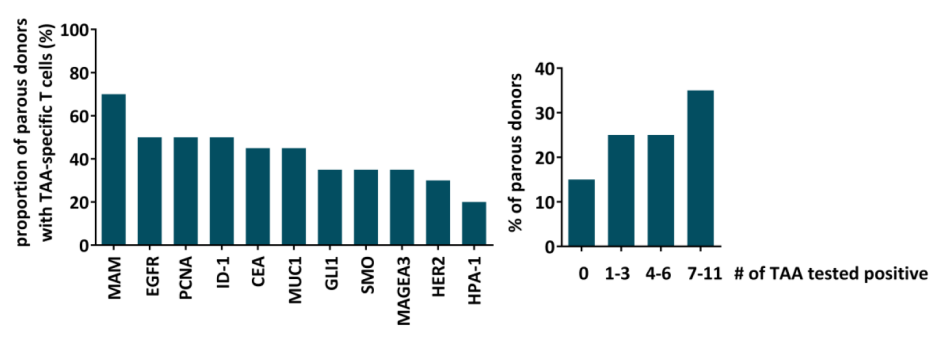

$\mathbf{F}$

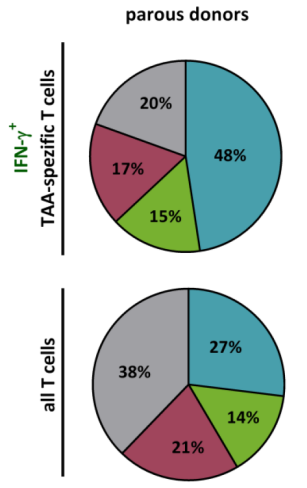

E

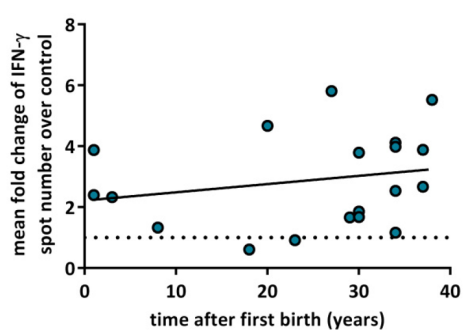

G

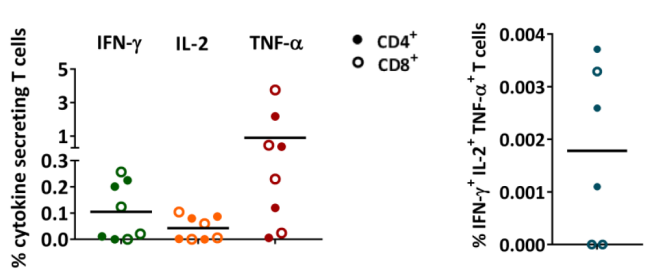

Figure 1: Tumor-associated antigen-reactive T cells are induced during pregnancy and persist for decades. (A) Primary data of two exemplary IFN- $\gamma$ ELISpot assays. Peripheral blood T cells of a healthy nulliparous and a healthy parous woman were stimulated with a (potential) TAA, the negative control antigen human IgG, or without antigen (DC, dendritic cells; TC, T cells), respectively. Data represent mean spot numbers of 3 wells per antigen \pm SEM. A T cell response was defined positive when spot numbers in test wells were at least 2 -fold higher and significantly $(\mathrm{p} \leq 0.05)$ higher compared to spot numbers of negative control antigen as determined with the unpaired 2 -tailed $t$ test. ${ }^{*} p \leq 0.05,{ }^{* *} p \leq 0.01$. (B-D) Cumulative results of IFN- $\gamma$ ELISpot assays. Data points depict the mean fold change of test antigens over negative control per healthy donor (with median \pm interquartile range). N: nullipara, p: para. P values were calculated using the unpaired 2-tailed $\mathrm{t}$ test comparing the pooled mean log fold change of test antigens over negative control. ${ }^{* * *} \mathrm{p} \leq 0.001,{ }^{* * * *} \mathrm{p} \leq$ 0.0001. (B) TAA-reactivity of peripheral T cells from nulliparous vs. parous women. (C) Proportion of parous females tested positive for single antigens (left) and number of antigens tested positive per donor (right). (D) Peripheral blood was also taken from primiparous women during pregnancy at weeks 14 or 21 , and within the first $24 \mathrm{~h}$ as well as 1 month after delivery. (E) TAA-reactivity of peripheral $\mathrm{T}$ cells from parous women in relation to the time after the donor's first delivery. Line: linear regression. (F) Memory phenotype of TAA-specific IFN- $\gamma$ secreting and total $\mathrm{T}$ cells, respectively, from four parous women. Mean percentage of naïve and stem cell-like memory T cells $\left(\mathrm{T}_{\mathrm{N}}, \mathrm{TSCM}\right.$, both $\left.\mathrm{CCR}^{+} \mathrm{CD} 45 \mathrm{RO}^{-}\right)$, central memory $\mathrm{T}$ cells $\left(\mathrm{T}_{\mathrm{CM}}, \mathrm{CCR} 7^{+} \mathrm{CD} 45 \mathrm{RO}^{+}\right)$, effector memory $\mathrm{T}$ cells $\left(\mathrm{T}_{\mathrm{EM}}, \mathrm{CCR}^{-} \mathrm{CD} 45 \mathrm{RO}^{+}\right)$, and terminally differentiated effector $\mathrm{T}$ cells $\left(\mathrm{T}_{\mathrm{E}}, \mathrm{CCR} 7^{-} \mathrm{CD} 45 \mathrm{RO}^{-}\right)$. (G) Cumulative results of cytokine secretion assays with $\mathrm{T}$ cells from healthy parous donors. Total $\mathrm{T}$ cells were stimulated with a TAA mixture or human IgG as a control. $\mathrm{CD} 4^{+}$and $\mathrm{CD} 8^{+} \mathrm{T}$ cells were analyzed separately. For gating strategy, see Supplementary Figure 3A. 
detected, but neither in the sister with abrupt pregnancies, nor in the nulligravid one (Supplementary Figure 2E).

In order to find out at which time during or after pregnancy TAA-specific $\mathrm{T}$ cell responses occur, we studied blood samples of altogether 29 healthy primigravid females in gestation weeks 14 or 21 , as well as within 24 hours and 4 weeks after delivery. Four volunteers donated blood at both postpartum time points. IFN- $\gamma$ ELISpot analyses revealed a strong $\mathrm{T}$ cell reactivity against TAA already in gestation week 14 (Figure 1D), and no further increases were observed at later time points during or after pregnancy. Nor was a decrease detected in TAA-specific T cell reactivity with time elapsing after parturition. Rather, our results indicate that a breast tumor antigen-specific $\mathrm{T}$ cell memory can be maintained for at least 4 decades (Figure 1E).

For confirmation, we analyzed the memory phenotype of TAA-specific T cells in parous females via flow cytometry. For that purpose, peripheral blood $\mathrm{T}$ cells were stimulated with autologous dendritic cells pulsed with a mixture of four TAA or control antigen (IgG), a triple cytokine secretion assay (IFN- $\gamma$, IL-2, and TNF- $\alpha$ ) was performed and, subsequently, the $\mathrm{T}$ cells were stained with fluorescently labelled antibodies against CCR7, CD45RO, CD4 and CD8 (for gating strategy, see Supplementary Figure 3). In each sample, the majority of IFN- $\gamma$-secreting TAA-specific T cells had an effector memory $\mathrm{T}$ cell phenotype $\left(\mathrm{T}_{\mathrm{EM}}, \mathrm{CCR}^{-} \mathrm{CD}^{-} 5 \mathrm{RO}^{+}\right.$, mean: $48 \%$ ), followed by lower proportions of central memory $\left(\mathrm{T}_{\mathrm{CM}}, \mathrm{CCR}^{-} \mathrm{CD}^{-} \mathrm{RO}^{+}\right)$, terminally differentiated effector $\left(\mathrm{T}_{\mathrm{E}}, \mathrm{CCR}^{-} \mathrm{CD}^{-} \mathrm{R}^{-} \mathrm{R}^{-}\right)$, and (likely) stem celllike memory $\mathrm{T}$ cells $\left(\mathrm{T}_{\mathrm{SCM}}, \mathrm{CCR} 7^{+} \mathrm{CD} 45 \mathrm{RO}^{-}\right)$(Figure $1 \mathrm{~F})$. We assume that the $\mathrm{CCR}^{+} \mathrm{CD}^{+} 5 \mathrm{RO}^{-}$cytokinesecreting population comprises $\mathrm{T}_{\mathrm{SCM}}$, since naïve $\mathrm{T}$ cells do not secrete cytokines even $24 \mathrm{~h}$ after stimulation with antibody-coupled beads against CD3, CD2 and CD28 and, in our assay, antigen presentation by dendritic cells was allowed for $12 \mathrm{~h}$ only. Analyses detected both $\mathrm{CD}^{+}$ and $\mathrm{CD}^{+} \mathrm{T}$ cells secreting IFN- $\gamma, \mathrm{TNF}-\alpha$ and IL- 2 in response to TAA. However, there was only a small proportion of polycytokine producing T cells (Figure 1G). Taken together, our results indicate that both $\mathrm{CD}^{+}$and $\mathrm{CD}^{+}$memory $\mathrm{T}$ cells specific for multiple breast tumorassociated antigens are induced during pregnancy and persist for decades.

\section{TAA-specific regulatory $T$ cells control effector $T$ cell responses during the breastfeeding period}

To investigate whether parity-induced effector $\mathrm{T}$ cell responses are controlled via TAA-specific regulatory $\mathrm{T}$ cells, we performed all ELISpot assays before and after the depletion of $\mathrm{CD}^{+} \mathrm{CD} 25^{+}$regulatory T cells. As shown in Figure 2A, the depletion of Treg cells did not have an overall significant effect on the $\mathrm{T}$ cell responsiveness. In individual cases, however, the Treg depletion resulted in a marked increase of IFN- $\gamma$ spot numbers - especially in 4 out of 6 primiparous women. Among the 4 females who donated blood 24 hours and 4 weeks after delivery, we detected strong TAA-specific T cell responses in two donors. These responses were vigorously suppressed by regulatory $\mathrm{T}$ cells after 4 weeks of breastfeeding, but not yet directly after delivery (Supplementary Figure 4). We thus studied the presence of TAA-specific Treg cells by a functional assay [18], which assesses the increased suppressive activity of Treg cells after antigen-specific stimulation. Primary data of two representative Treg cell-specificity experiments are presented in Figure 2B. A positive response was defined by significantly reduced Tcon proliferation after coculture with autologous TAAstimulated Treg compared to controls with IgG-stimulated Treg cells (asterisks, red bars). Pooled results are shown in Figure 2C, representing the proportions of antigens tested positive per donor. TAA-specific regulatory $\mathrm{T}$ cells were detected in all groups, with the highest proportion of positive tests in primiparous women who had delivered four weeks before blood samples were taken. There was a significant increase in the number of TAAs recognized by Treg cells of primigravid compared to parous females, suggesting that more TAA-specific regulatory $\mathrm{T}$ cells are induced or expand after delivery. Among those healthy mothers with detectable TAA-reactive memory $\mathrm{T}$ lymphocytes, about one third also displayed Treg cells specific for at least one of the same antigens (Supplementary Table 1) demonstrating that $\mathrm{T}$ effector and Treg responses can be elicited against the same antigen. In summary, we detected TAA-specific regulatory $\mathrm{T}$ cells in a proportion of healthy individuals. They strictly control strong effector $\mathrm{T}$ cell responses during the breastfeeding period.

\section{TAA-specific $T$ cell responses are improved in parous compared to nulliparous patients with breast cancer}

We next investigated how TAA-specific $T$ cell responses might be altered during breast cancer progression. Therefore, before tumor resection, we collected peripheral blood samples from 64 females (median age: 54 years; mean $55.76 \pm 11.36$ ) diagnosed with pure ductal carcinoma in situ (DCIS) or invasive breast cancer. The respective results of IFN- $\gamma$ ELISpot assays are presented in Figures 3A-3D. T cell responses against TAA were detectable in both nulliparous women with preinvasive (in situ) and invasive breast cancer. In both groups, the reactivity was significantly stronger than that in nulliparous healthy females (Figures 3A, 3B). Again, the results were not biased by different background noises (Supplementary Figure 5). Regarding the antigen specificities of $\mathrm{T}$ cells from healthy subjects compared to breast cancer patients, we detected no major differences (Supplementary Figure 6). Median $\mathrm{T}$ cell responses 
against TAA were 2.8-fold stronger in parous compared to nulliparous patients with invasive breast cancer and we detected significantly more marked responses against single antigens (Figure 3C). However, in $\mathrm{T}$ cells from nulliparous breast cancer patients, the TAA responsiveness could be restored after Treg cell depletion, while T cells from parous patients were not influenced (Figure 3D). Nevertheless, TAA-specific Treg cells were frequently detected in both groups (Supplementary Figures 7-9).

Eventually, we compared the relation of TAAspecific effector to regulatory $\mathrm{T}$ cells in nulliparous and parous breast cancer patients. While there was a strong

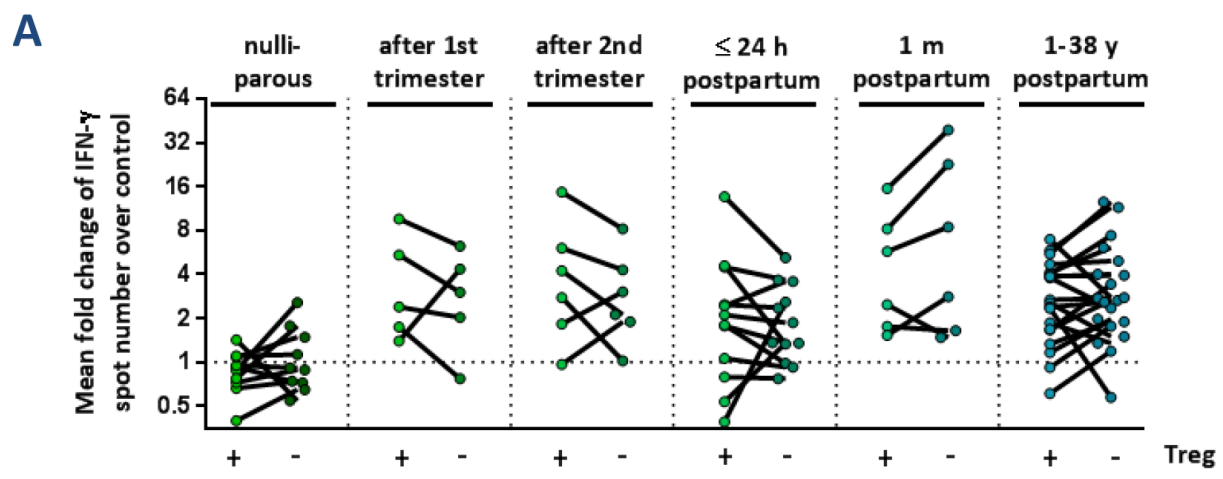

B
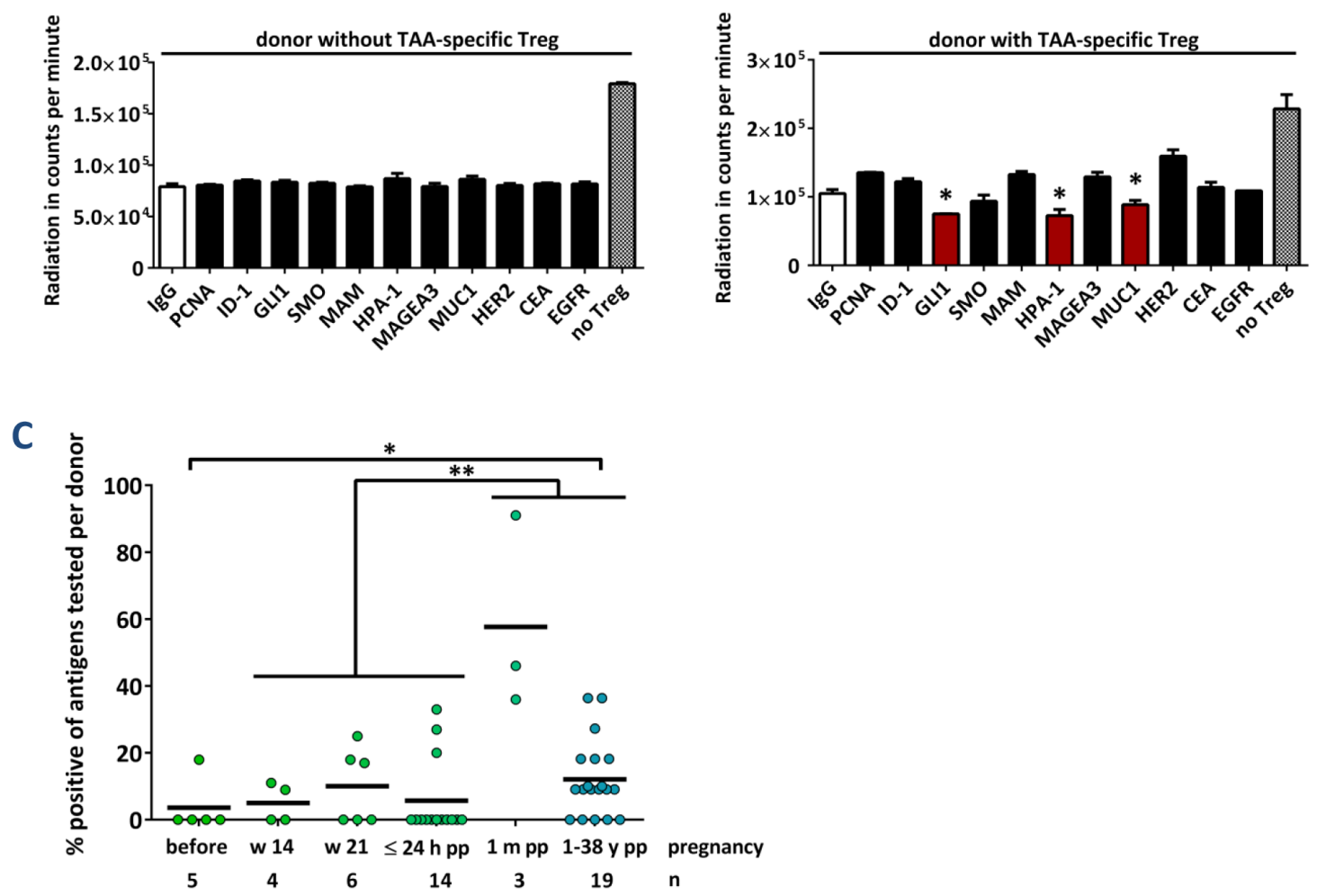

Figure 2: TAA-reactive T cells are suppressed via regulatory $\mathbf{T}$ cells after delivery. (A) Cumulative results of IFN- $\gamma$ ELISpot assays before ( + ) and after (-) depletion of $\mathrm{CD}^{+} \mathrm{CD} 25^{+}$regulatory T cells (Treg). Data points depict the mean fold change of test antigens over negative control per healthy donor with median \pm interquartile range. Peripheral blood was taken from nulliparous women, from primiparous women during pregnancy at weeks 14 or 21 , from primiparous women during the first $24 \mathrm{~h}$ after delivery, from primiparous women 1 month after delivery, and from parous women whose last pregnancy was at least 1 year before. $\mathrm{P}$ values were calculated using the unpaired 2-tailed t test comparing the pooled mean log fold change of test antigens over negative control. (B) Primary data of two exemplary regulatory $\mathrm{T}$ cell-specificity assays. Bars represent the mean radiation in counts per minute in 3 wells per antigen \pm SEM. Suppression of proliferation by antigen-reactive Treg cells was determined by a significantly $(\mathrm{p} \leq 0.05$, unpaired $\mathrm{t}$ test) reduced radiation in test wells compared to the negative control IgG. ${ }^{*} \mathrm{p} \leq 0.05$. No Treg: Proliferation control including DCs with polyclonally activated TC without autologous Treg cells. (C) Cumulative results of regulatory TC-specificities in healthy individuals. Data points show the percentage of positive tests per donor. The ratio of individuals with TAA-reactive Treg cells was compared using Fisher's exact test. Cumulative data of all individuals during or instantly after pregnancy compared to donors 1 month to 38 years after childbirth ${ }^{* *} \mathrm{p} \leq 0.01$. Cumulative data of all individuals during or instantly after pregnancy compared to donors 1 year to 38 years after childbirth ${ }^{*} \mathrm{p} \leq 0.05$. 

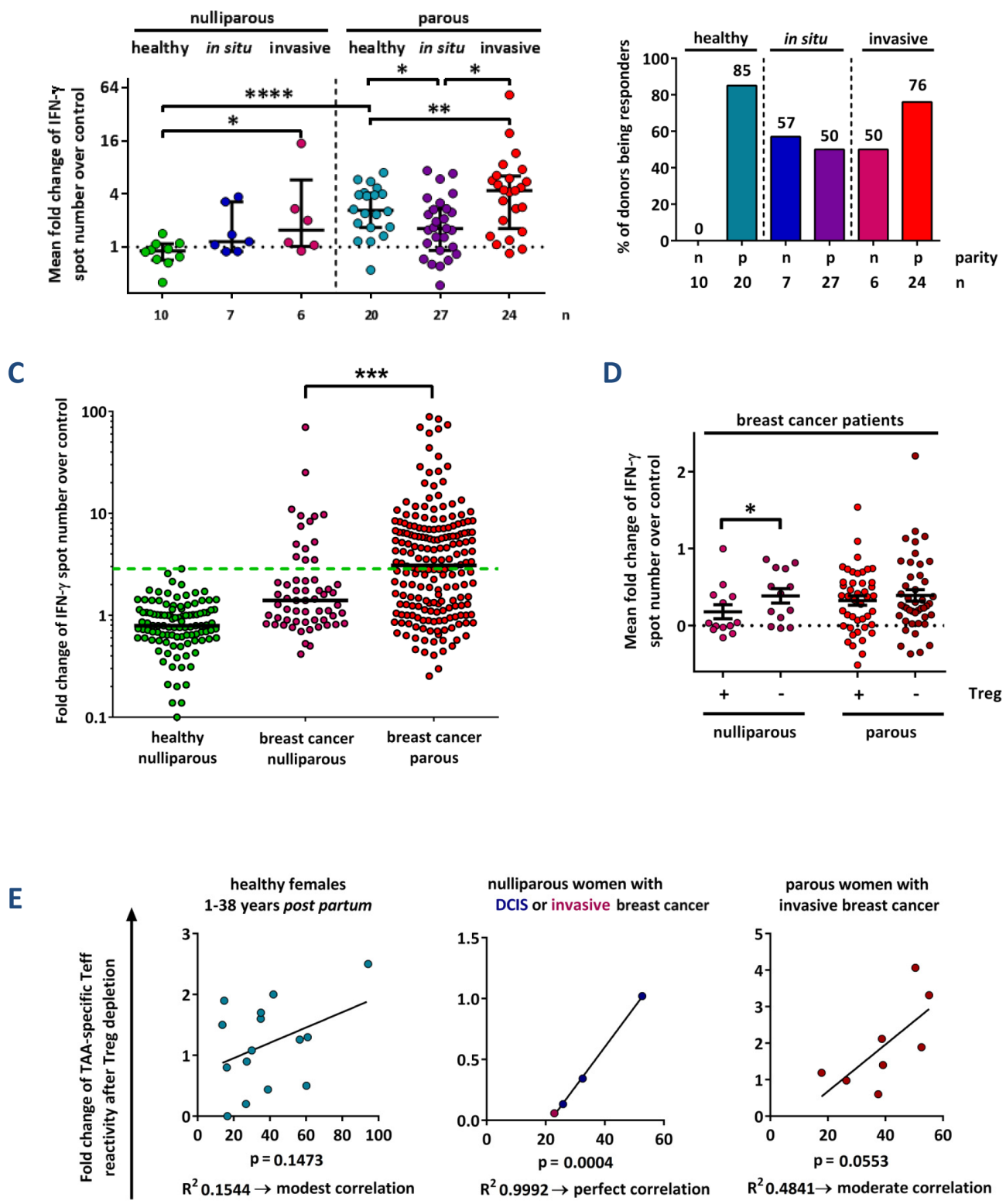

$\%$ suppression of Tcon proliferation by TAA-specific Treg cells

Figure 3: Parity improves TAA-specific T cell responses in breast cancer patients. (A) Cumulative results of IFN- $\gamma$ ELISpot analyses from healthy donors, patients with mammary ductal carcinoma in situ (DCIS), and patients with invasive breast cancer. Data points depict the mean fold change of test antigens over negative control per donor with median \pm interquartile range. P values were calculated using the unpaired 2-tailed t test comparing the pooled mean log fold change of test antigens over negative control between healthy donors, patients with DCIS and patients with invasive carcinomas. ${ }^{*} \mathrm{p} \leq 0.05,{ }^{* *} \mathrm{p} \leq 0.01,{ }^{* * * *} \mathrm{p} \leq 0.0001$. (B) The percentage of nulliparous (n) and parous (p) females tested positive for at least one peptide in the total TC fraction is depicted. (C) Single test results of ELISpot assays according to the parity status of breast cancer patients. The mean change in spot number per antigen in test holes compared to the negative control (IgG) is shown. The proportion of T cell responses above the highest value measured in nulliparous healthy donors (green dashed line) was compared using Fisher's exact test. ${ }^{* * *}: \mathrm{p} \leq 0.001$. Median values are shown as solid lines. (D) Cumulative test results of ELISpot assays according to the parity status of breast cancer patients. Data points depict the mean fold change of test antigens over negative control per healthy donor with mean \pm SEM. Assays were performed before $(+)$ and after $(-)$ depletion of CD4+ CD25+ regulatory T cells (Treg). The significance of the effect of Treg cell depletion was calculated with the paired 2-tailed $t$ test comparing the pooled mean log fold change of test antigens over negative control between the Treg cell-depleted and total T cell fractions obtained from the same donors. ${ }^{*} \mathrm{p} \leq 0.05$. (E) Relation of TAA-specific IFN- $\gamma$-secreting "conventional" T cells (Tcon) to TAA-specific regulatory T cells (Treg) per donor. Correlation of fold increase of IFN- $\gamma$ spot number after depletion of Treg cells determined via ELISpot assay versus the percentage of suppression using the same antigen measured in the Treg specificity assay. Data pairs are selected from identical blood samples and include only antigens tested positive in the Treg specificity assay. Linear regression analysis was performed to calculate the goodness of fit $\left(\mathrm{R}^{2}\right)$ and the $\mathrm{p}$ value. 
correlation in nulliparous breast cancer patients, it was moderate in parous breast cancer subjects and weak in healthy parous females (Figure $3 \mathrm{E}$ ). We thus conclude that in a proportion of nulliparous women, spontaneous $\mathrm{T}$ cell responses against breast tumor-associated antigens are induced during breast cancer development. However, these $\mathrm{T}$ cell responses are more strictly controlled by Treg cells than in parous breast cancer patients.

\section{DISCUSSION}

This study adds six important findings to the previous observation that a $\mathrm{T}$ cell response against a single breast cancer-associated antigen, MUC-1, is induced during the first trimester of pregnancy [16]. First, spontaneous $\mathrm{T}$ cell responses against TAA can be detected in most parous, but not in nulliparous women. Second, T cell reactivity is directed against a wide range of various breast cancer- associated antigens. Third, pregnancy results in the formation of a lifelong TAAspecific memory. Fourth, TAA-specific $\mathrm{T}$ cells have a mixed memory phenotype. Fifth, healthy females also harbor TAA-specific regulatory $\mathrm{T}$ cells, which control strong TAA-specific conventional T cell responses, e. g., during the breastfeeding period. Finally, in nulliparous breast cancer patients, anti-tumor $\mathrm{T}$ cell responses are weaker than those in parous patients, but can be enhanced via depletion of TAA-specific Treg cells.

Since spontaneous TAA-specific effector $\mathrm{T}$ cell responses correlate with a significantly improved prognosis [4-7], pregnancy-induced preexisting TAAspecific $\mathrm{T}$ cell responses may also protect from breast cancer development. In animal models, at least, this has already been demonstrated in that splenocytes from parous rats compared to those from nulliparous rats have revealed a significantly higher cytotoxic activity against mammary tumors in vivo [18]. Furthermore, the adoptive transfer of those splenocytes from parous rats into virgin counterparts resulted in a reduced carcinogen-induced mammary tumorigenesis [19]. Additional studies showed that this pregnancy-associated cytolysis was mediated by $\mathrm{T}$ cells in a cell contact-dependent manner.

A possible mechanism behind the induction of TAA-specific $\mathrm{T}$ cell responses during pregnancy is an increased expression of shared tumor- and pregnancyassociated antigens in the maturing mammary gland, fetus and/or placenta. During the first trimester of pregnancy, ductal epithelial cells of the breast undergo final differentiation and massive proliferation occurs. At this time, lymphocytes begin to accumulate in the interstitial tissue of the breast, which concurs with the induction of many breast tumor-associated antigens highly expressed in the lactating breast [13]. A previous study reported the presence of activated effector/memory $\mathrm{T}$ cells in breast milk, which recognized maternal epithelial surfaces [20]. Hence, there is accumulating evidence supporting the hypothesis that pregnancy implies a robust and longlasting natural immunization against multiple tumorassociated antigens.

In this study, we demonstrated that pregnancy was also associated with an increased occurrence of TAAreactive regulatory $\mathrm{T}$ (Treg) cells in approximately two thirds of healthy mothers. These often reacted against the same antigens as TAA-reactive effector/memory T cells, suggesting that peripheral tolerance might be induced to prevent autoimmune-mediated destruction of the breast. Notably, a significant increase in Treg cell responses occurred during lactation, which is in line with the observation that Treg highly infiltrate the human breast four weeks post partum [21].

In parous women, $\mathrm{T}$ cell responsiveness was not influenced by reproductive factors known to affect breast cancer risk, such as age at first childbirth or the breastfeeding history. The latter concurs with the finding that the protective impact of breastfeeding on breast cancer does not emerge until after more than 3 births [1], which applied for none of our donors. Although the lowest breast cancer risk reportedly pertains to women who had their first birth at a young age [1], we could not find superior $\mathrm{T}$ cell responses in mothers who had delivered early in life. Thus, assuming that the breast cancer protective effect of parity is at least partially mediated by the induction of TAA-reactive T cells, this effect might not depend on the degree of $\mathrm{T}$ cell responsiveness, but rather on the early onset and long duration of the immune protection.

Parity also strongly affected $\mathrm{T}$ cell immunity in breast cancer patients. Although we observed TAAspecific $\mathrm{T}$ cell responses in nulliparous patients with preinvasive and invasive breast cancer, these were weaker and more strongly suppressed by TAA-specific Treg particularly at preinvasive stages - than those from parous breast cancer patients. We indeed detected an increased generation of TAA- reactive Treg throughout the course of breast cancer development - at least in a proportion of patients - which is in line with previous findings that Treg accumulation increases from normal tissue over ductal carcinoma in situ to invasive breast cancer [22].

It remains to be determined yet if the spontaneous induction of TAA-specific $\mathrm{T}$ cells during pregnancy eventually results in a reduced breast cancer incidence and improved prognosis in case that breast cancer still develops. Future prospective studies along these lines might provide valuable criteria to select suitable antigens for the formulation of a preventive breast cancer vaccine. Hence, since nulliparity is becoming more common in the industrialized countries and as there is a strongly increased breast cancer incidence in these women, the development and application of a preventive vaccine would be both reasonable and desirable. Clearly, to this end further studies are still needed to elucidate the mechanisms of parity-mediated breast cancer protection. Recently, for instance, alterations in Wnt and TGF $\beta$ 
Table 1: Tumor antigens and synthetic long peptides

\begin{tabular}{lrl}
\hline Tumor-associated antigen & $\begin{array}{c}\text { Peptide } \\
\text { position }\end{array}$ & Peptide sequence \\
\hline $\begin{array}{l}\text { Proliferating cell nuclear antigen } \\
\text { (PCNA) [27] }\end{array}$ & $201-250$ & EPVQLTFALRYLNFFTKATPLSSTVTLSMSADVPLVVEYKIADMGHLKYN \\
$\begin{array}{l}\text { Inhibitor of differentiation 1 (ID-1) } \\
\text { [23] }\end{array}$ & $101-146$ & YIRDLQLELNSESEVGTPGGRGLPVRAPLSTLNGEISALTAEAACV \\
$\begin{array}{l}\text { Glioma-associated oncogene 1 } \\
\text { (GLI1) [24] }\end{array}$ & $365-411$ & KLPGCTKRYTDPSSLRKHVKTVHGPDAHVTKRHRGDGPLPRAPSIST \\
Smoothened (SMO) [25] & $557-603$ & DDEPKRIKKSKMIAKAFSKRHELLQNPGQELSFSMHTVSHDGPVAGL \\
Mammaglobin A (Mam1) [9] & $4-56$ & LMVLMLAALSQHCYAGSGCPLLENVISKTINPQVSKTEYKELLQEFIDDNATT \\
Heparanase 1 (HPA1) [11] & $1-50$ & MLLRSKPALPPPLMLLLLGPLGPLSPGALPRPAQAQDVVDLDFFTQEPLH \\
MUC1 [9] & $137-157$ & (GVTSAPDTRPAPGSTAPPAH)x5 \\
MAGEA3 [9] & $271-314$ & FLWGPRALVETSYVKVLHHMVKISGGPHISYPPLHEWVLREGEE \\
CEA [9] & $569-618$ & YVCGIQNSVSANRSDPVTLDVLYGPDTPIISPPDSSYLSGANLNLSCHSA \\
HER2/neu [9] & $351-384$ & REVRAVTSANIGEFAGCKKIFGSLAFLPESFDGD \\
EGFR [10] & $479-528$ & KLFGTSGQKTKIISNRGENSCKATGQVCHALCSPEGCWGPEPRDCVSCRN \\
\hline
\end{tabular}

signaling pathways in mammary stem/progenitor cells have revealed new potential targets for preventive interventions [28].

\section{MATERIALS AND METHODS}

\section{Patients}

Peripheral blood samples were obtained from 59 healthy donors and 64 patients with primary breast cancer without neoadjuvant therapy before primary surgery. 34 patients had a histologically approved pure ductal carcinoma in situ and 30 had invasive breast carcinoma. Informed consent was obtained from all participants. The study protocol was approved by the Ethical Committee of the University of Heidelberg.

\section{Cell culture and purification}

PBMCs were collected from blood samples after Ficoll density gradient centrifugation (Biochrom, Berlin, Germany), washed and cultured in X-VIVO 20 medium (Lonza, Verviers, Belgium) for $1 \mathrm{~h}$. Non-adherent cells were transferred to $X$-VIVO 20 medium with $100 \mathrm{U} / \mathrm{ml}$ IL-2 (Novartis, Basel, Switzerland) and $60 \mathrm{U} / \mathrm{ml} \mathrm{IL-4}$ (Miltenyi Biotec, Bergisch Gladbach, Germany). X-VIVO 20 medium supplemented with $50 \mathrm{ng} / \mathrm{ml}$ GM-CSF (SanofiAventis, Frankfurt, Germany) and 1,000 U/ml IL-4 was added to adherent cells. The cells were cultivated for 5 to $10 \mathrm{~d}$ and subsequently deprived of cytokines for $24 \mathrm{~h}$.

Dendritic cells were enriched by negative selection using Pan Mouse IgG Dynabeads ${ }^{\circledR}$ (Life Technologies,
Darmstadt, Germany), coupled to mouse anti-human CD3, CD19 and CD56 antibodies, respectively. T cell purification was performed using the UntouchedTM Human T Cells system (Life Technologies). After removal of $2.5 \times 10^{6} \mathrm{~T}$ lymphocytes as non-Treg cell depleted fraction for the ELISpot assay, the remaining $\mathrm{T}$ lymphocytes were depleted from Treg cells using the $\mathrm{CD}^{+} \mathrm{CD}^{+} 5^{+}$Regulatory $\mathrm{T}$ Cell Isolation Kit (Miltenyi Biotec).

\section{Antigens}

As TAA, we used long synthetic peptides (LSP) from seven well-characterized breast tumor-associated antigens: CEA, MAGE-A3, MUC-1, EGFR, HER2/ neu, mammaglobin $\mathrm{A}$, heparanase 1 and proliferating cell nuclear antigen (PCNA) and from some breast TAA without proven $T$ cell reactivity: Inhibitor of differentiation (ID)-1 [23], glioma-associated oncogene homologue (GLI)-1 [24], and smoothened (SMO) [25]. As negative control antigen, we used human IgG. All LSP were designed to contain multiple HLA-A*01, HLA-A*0201, HLA-A*03 and HLA-B*0702 T cell epitopes, according to in silico prediction using SYFPEITHI, BIMAS and NetMHC 3.2, or experimentally confirmed HLA-A*0201 T cell epitopes, if available. As a positive control for overall assay performance, we used the bacterial superantigen enterotoxin type B (Sigma-Aldrich, St Louis, Missouri, 1 $\mu \mathrm{g} / \mathrm{ml})$.

The amino acid sequences of respective peptides are summarized in Table 1. 


\section{IFN- $\gamma$ ELISpot assay}

The IFN- $\gamma$ ELISpot assay was performed as described previously [26], with modifications.

In brief, $1 \times 10^{4}$ dendritic cells were pulsed with 200 $\mu \mathrm{g} / \mathrm{ml}$ test peptide or human IgG as negative control in triplicates. After $14 \mathrm{~h}$ of incubation, $5 \times 10^{4} \mathrm{~T}$ cells were added. For each sample, the assay was performed with total $\mathrm{T}$ lymphocytes and a Treg cell-depleted fraction, respectively. After $40 \mathrm{~h}$ of co-culture, IFN- $\gamma$ secreting T cells were visualized using an enzyme-coupled detection antibody system (Mabtech, Nacka Strand, Sweden). Plates were analyzed using an automated system (CTL, Bonn, Germany) and subjected to a manual quality control.

\section{Treg cell specificity assay}

The Treg cell specificity assay was performed as described previously [26], with modifications.

$5 \times 10^{3}$ dendritic cells were pulsed with $200 \mu \mathrm{g} /$ $\mathrm{ml}$ test peptide or human IgG in triplicates. After 14 $\mathrm{h}$ of incubation, $2.5 \times 10^{4} \mathrm{CD} 4^{+} \mathrm{CD} 25^{+}$Treg cells were added. Simultaneously, autologous Treg cell-depleted $\mathrm{T}$ lymphocytes (Tcon) were polyclonally activated in a plate coated with anti-human CD3 antibody. After 18 $\mathrm{h}$ of incubation, $2.5 \times 10^{4}$ Tcon were added. After $72 \mathrm{~h}$ of culture, ${ }^{3} \mathrm{H}$-thymidine at $37 \mathrm{KBq}$ was added. $\mathrm{T}$ cell proliferation was measured by determining the amount of incorporated ${ }^{3} \mathrm{H}$ using the liquid scintillation counter 1450 MicroBeta (PerkinElmer, Waltham Massachusetts, USA).

\section{IFN- $\gamma$ secretion assay}

$1 \times 10^{5}$ DC were pulsed with $100 \mu \mathrm{g}$ of a mixture of polypeptides (ID-1, mammaglobin-A, MUC1, and heparanase 1) or human IgG. $8 \mathrm{~h}$ later, $5 \times 10^{5} \mathrm{TC}$ were added. After $12 \mathrm{~h}$ of coincubation, unspecific binding to Fc receptors was blocked by preincubation of cells for 20 minutes with human IgG (Sandoglobin, Sigma-Aldrich, Taufkirchen, Germany). Secreted IFN- $\gamma$ was captured and fluorescently labelled using the MACS human IFN- $\gamma$ Secretion Assay Detection Kit (Miltenyi), according to the manufacturer's instructions. Subsequently, TC were stained for CD4, CD8, CD45RO, CCR7 (clones RPA-T4, RPA-T8, UCHL1 and 3D12, respectively, all from BD Biosciences, Heidelberg, Germany) and viability (LIVE/ DEAD Fixable Yellow Dead Cell Stain, BD). Isotype control stainings were performed using corresponding isotype antibodies. Samples were analyzed using a FACS Canto II flow cytometer (BD) and FlowJo software (vX, TreeStar, Ashland, USA).

\section{Statistical evaluation}

$\mathrm{T}$ cell reactivity in ELISpot experiments was calculated as the fold increase of spot numbers in test wells over that in negative control wells, as a mean of all tests per patient. A response was defined positive when test wells had at least twofold higher spot counts than the negative control wells and the difference was significant in the unpaired 2-tailed $t$ test. Cumulative ELISpot data were analyzed as pooled mean log fold change of test antigens over negative control. The unpaired 2-tailed t test was used to compare different groups of donors. The effect of Treg cell-depletion within the same group was assessed by the paired 2-tailed $t$ test.

The presence of TAA-specific Treg cells was defined positive when test peptide wells had significantly lower scintillation counts than negative control wells, as determined by unpaired 2-tailed t test. Proportions of responders were compared between groups using the Fisher's exact test. Differences were considered statistically significant when $\mathrm{p} \leq 0.05$.

\section{Authors' contributions}

Authorship was designated based on the guidelines promulgated by the International Committee of Medical Journal Editors (2004). All persons who meet criteria for authorship are listed as authors on the title page. The contribution of each of these persons to this study is as follows: ALK, PB and CD made substantial contributions to the conception and design, interpreted the data, and prepared and edited the manuscript. FS, MB, MW, MG, $\mathrm{JR}$, and $\mathrm{JH}$ contributed to the acquisition, analysis, and interpretation of the data. FS and MP checked the quality of the data. FS, CS and AS critically revised the manuscript for important intellectual content. All authors read and approved the final manuscript.

\section{ACKNOWLEDGMENTS}

We thank Joanna Förster for expert technical support.

\section{CONFLICTS OF INTEREST}

No potential conflicts of interest were disclosed by the authors.

\section{GRANT SUPPORT}

None

\section{REFERENCES}

1. Faupel-Badger JM, Arcaro KF, Balkam JJ, Eliassen AH, Hassiotou F, Lebrilla CB, Michels KB, Palmer JR, Schedin P, Stuebe AM, Watson CJ, Sherman ME. Postpartum remodeling, lactation, and breast cancer risk: summary of a National Cancer Institute-sponsored workshop. J Natl Cancer Inst. 2013; 105:166-174. 
2. Coulie PG, Van den Eynde BJ, van der Bruggen P, Boon $\mathrm{T}$. Tumour antigens recognized by $\mathrm{T}$ lymphocytes: at the core of cancer immunotherapy. Nat Rev Cancer. 2014; 14:135-146.

3. Feuerer M, Beckhove P, Bai L, Solomayer EF, Bastert G, Diel IJ, Pedain C, Oberniedermayr M, Schirrmacher V, Umansky V. Therapy of human tumors in NOD/SCID mice with patient-derived reactivated memory $\mathrm{T}$ cells from bone marrow. Nat Med. 2001; 7:452-458.

4. Bailur J, Gueckel B, Derhovanessian E, Pawelec G. Presence of circulating Her2-reactive CD8+ T-cells is associated with lower frequencies of myeloid-derived suppressor cells and regulatory $\mathrm{T}$ cells, and better survival in older breast cancer patients. Breast Cancer Res. 2015; $17: 34$.

5. Domschke C, Schuetz F, Ge Y, Seibel T, Falk C, Brors B, Vlodavsky I, Sommerfeldt N, Sinn HP, Kühnle MC, Schneeweiss A, Scharf A, Sohn C, et al. Intratumoral cytokines and tumor cell biology determine spontaneous breast cancer-specific immune responses and their correlation to prognosis. Cancer Res. 2009; 69:8420-8428.

6. Mahmoud SM, Paish EC, Powe DG, Macmillan RD, Grainge MJ, Lee AH, Ellis IO, Green AR. Tumorinfiltrating CD8+ lymphocytes predict clinical outcome in breast cancer. J Clin Oncol. 2011; 29:1949-1955.

7. Bates GJ, Fox SB, Han C, Leek RD, Garcia JF, Harris AL, Banham AH. Quantification of regulatory T cells enables the identification of high-risk breast cancer patients and those at risk of late relapse. J Clin Oncol. 2006; 24:5373-5380.

8. Ge Y, Domschke C, Stoiber N, Schott S, Heil J, Rom J, Blumenstein M, Thum J, Sohn C, Schneeweiss A, Beckhove P, Schuetz F. Metronomic cyclophosphamide treatment in metastasized breast cancer patients: immunological effects and clinical outcome. Cancer Immunol Immunother. 2012; 61:353-362.

9. Novellino L, Castelli C, Parmiani G. A listing of human tumor antigens recognized by T cells: March 2004 update. Cancer Immunol Immunother. 2005; 54:187-207.

10. Stebbing J, Thiyagarajan A, Surendrakumar V, Payne R, Krell J, Szydlo R, Peston D, Lewis JS, Coombes RC, Shousha S. Epidermal growth factor receptor status in early stage breast cancer is associated with cellular proliferation but not cross-talk. J Clin Pathol. 2011; 64:829-831.

11. Sommerfeldt N, Beckhove P, Ge Y, Schutz F, Choi C, Bucur M, Domschke C, Sohn C, Schneeweis A, Rom J, Pollmann D, Leucht D, Vlodavsky I, et al. Heparanase: a new metastasis-associated antigen recognized in breast cancer patients by spontaneously induced memory T lymphocytes. Cancer Res. 2006; 66:7716-7723.

12. Caballero OL, Shousha S, Zhao Q, Simpson AJG, Coombes RC, Neville AM. Expression of Cancer/Testis genes in ductal carcinoma in situ and benign lesions of the breast. Oncoscience. 2014; 1:14-20. https://doi.org/10.18632/ oncoscience. 4 .
13. Arklie J, Taylor-Papadimitrious J, Bodmer W, Egan M, Millis R. Differentiation antigens expressed by epithelial cells in the lactating breast are also detectable in breast cancers. Int J Cancer. 1981; 28:23-29.

14. Jungbluth AA, Silva WA Jr, Iversen K, Frosina D, Zaidi B, Coplan K, Eastlake-Wade SK, Castelli SB, Spagnoli GC, Old LJ, Vogel M. Expression of cancer-testis (CT) antigens in placenta. Cancer Immun. 2007; 7:15.

15. Finn OJ, Jerome KR, Henderson RA, Pecher G, Domenech N, Magarian-Blander J, Barratt-Boyes SM. MUC-1 epithelial tumor mucin-based immunity and cancer vaccines. Immunol Rev. 1995; 145:61-89.

16. Agrawal B, Reddish MA, Krantz MJ, Longenecker BM. Does pregnancy immunize against breast cancer? Cancer Res. 1995; 55:2257-2261.

17. Erlebacher A. Mechanisms of T cell tolerance towards the allogeneic fetus. Nat Rev Immunol. 2013; 13:23-33.

18. Chakravarty PK, Ghosh SK, Sinha DK. Pregnancy-induced cytotoxicity of splenocytes against mammary tumor cells in rats. Oncology. 1991; 48:425-430.

19. Chakravarty PK, Sinha DK. Inhibition of mammary tumorigenesis in virgin rats by adoptive transfer of splenocytes from parous donors. Cancer Immunol Immunother. 1991; 33:263-266.

20. Sabbaj S, Ibegbu CC, Kourtis AP. Cellular immunity in breast milk: implications for postnatal transmission of HIV-1 to the infant. Adv Exp Med Biol. 2012; 743:161-169.

21. Martinson HA, Jindal S, Durand-Rougely C, Borges VF, Schedin P. Wound healing-like immune program facilitates postpartum mammary gland involution and tumor progression. Int J Cancer. 2015; 136:1803-1813.

22. Gupta S, Joshi K, Wig JD, Arora SK. Intratumoral FOXP3 expression in infiltrating breast carcinoma: its association with clinicopathologic parameters and angiogenesis. Acta Oncol. 2007; 46:792-797.

23. Liu Q, Yang YM, Zhang QH, Zhang TG, Zhou Q, Zhou CJ. Inhibitor of differentiation is overexpressed with progression of benign to malignant lesions and related with carcinoembryonic antigen-related cell adhesion molecule 1 distribution in mammary glands. Ann Diagn Pathol. 2011; 15:30-36.

24. Souzaki M, Kubo M, Kai M, Kameda C, Tanaka H, Taguchi T, Tanaka M, Onishi H, Katano M. Hedgehog signaling pathway mediates the progression of non-invasive breast cancer to invasive breast cancer. Cancer Sci. 2011; 102:373-381.

25. Moraes RC, Zhang X, Harrington N, Fung JY, Wu MF, Hilsenbeck SG, Allred DC, Lewis MT. Constitutive activation of smoothened (SMO) in mammary glands of transgenic mice leads to increased proliferation, altered differentiation and ductal dysplasia. Development. 2007; 134:1231-1242. 
26. Bonertz A, Weitz J, Pietsch DH, Rahbari NN, Schlude C, Ge Y, Juenger S, Vlodavsky I, Khazaie K, Jaeger D, Reissfelder C, Antolovic D, Aigner M, et al. Antigen-specific Tregs control $\mathrm{T}$ cell responses against a limited repertoire of tumor antigens in patients with colorectal carcinoma. J Clin Invest. 2009; 119:3311-3321.

27. Xu W, Li HZ, Liu JJ, Guo Z, Zhang BF, Chen FF, Pei DS, Zheng JN. Identification of HLA-A*0201-restricted cytotoxic $\mathrm{T}$ lymphocyte epitope from proliferating cell nuclear antigen. Tumour Biol. 2011; 32:63-69.

28. Meier-Abt F, Bentires-Alj M, Rochlitz C. Breast cancer prevention: lessons to be learned from mechanisms of early pregnancy-mediated breast cancer protection. Cancer Res. 2015; 75:803-807. 